\title{
CORD-BLOOD ANTISTREPTOLYSIN-O LEVEL ACCORDING. TO PARITY AND SOCIAL CLASS AS A POSSIBLE INDEX OF FAMILIAL STREPTOCOCCAL EXPERIENCE
}

\author{
By E. G. L. BY WATERS, F.R.C.P., E. J. HOLBOROW, M.D., \\ G. D. JOHNSON, F.I.M.L.T. AND R. J. KELLY, F.I.M.L.T. \\ From the Special Unit for Study and Care of Juvenile Rheumatism, \\ Canadian Red Cross Memorial Hospital, Taplow, Bucks, \\ and the Postgraduate Medical School of London
}

(With 1 Figure in the Text)

Group A haemolytic streptococcal upper respiratory infections occur most commonly in school-age children (Collins, 1929; Wannamaker, 1954). This group shows also a high incidence of raised antistreptolysin-O (A.s.o.) titres (Mote \& Jones, 1941). It might be expected that the families, and particularly the mothers of such children would, therefore, be exposed to more streptococcal infections than families and mothers with young children not yet at school, or than women without children as Hewitt \& Stewart (1952) have surmised. If such exposure resulted in infection of the mother, any increase in her serum A.s.o. titre present during a pregnancy should appear in the umbilical cord blood at delivery, since A.s.o. passes the placenta (Vahlquist, Lagncrantz \& Nordbring, 1950).

In the work reported here we have determined A.s.o. titres of cord-blood specimens taken at delivery of primiparae, and of multiparae with children either of school age or below it. We have also related the distribution of A.s.o. levels to the social class of the father, as suggested by the work of Holmes \& Rubbo (1953).

\section{MATERIALS AND METHODS}

(1) Cord blood was obtained from 480 unselected deliveries in hospital at two centres, Hammersmith Hospital and Taplow, during the period May 1955 to May 1956. The serum was separated as soon as possible, stored at $4^{\circ} \mathrm{C}$., and tested within 1 week.

(2) Details were obtained from the mother regarding her other children's school status, and the father's occupation, as an indication of social class (RegistrarGeneral's classification).

(3) Blood samples were obtained from twenty-five mothers at their 36-week ante-natal examination, and cord bloods were obtained from these same cases at the time of delivery, approximately 4 weeks later. These paired samples were used to test the relationship between maternal blood and cord-blood antistreptolysin-O levels.

(4) Antistreptolysin-O determinations were carried out at the two centres by a technique modified from that previously described (Johnson, 1955). The 
reciprocals of the dilutions of serum used were $25,50,75,100,200,300,400$. A stable antistreptolysin globulin of known strength was used to standardize the titration at both centres.

\section{RESULTS}

(1) A.s.o. levels in maternal blood and in cord blood

Fig. 1 shows that the A.s.o. titre of cord blood was usually somewhat higher than the titre of ante-natal blood taken from the mother about 4 weeks before delivery. The mean ratio of the two was approximately $\mathbf{l} \cdot 6$.

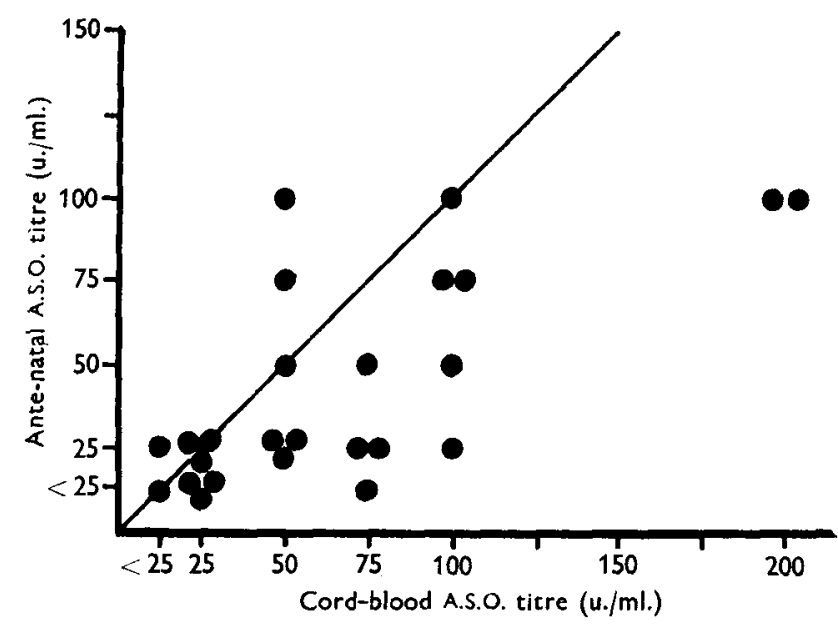

Fig. 1. Scatter diagram showing relationship of A.s.o. levels in twenty-five pairs of maternal and cord-blood samples.

(2) A.s.o. levels at the two centres

A comparison of A.s.o. levels in cord bloods from the two hospital centres is shown in Table 1. The distribution of levels is not significantly different at the two centres, except for low values of 25 units/ml. or less; in this range the Taplow

Table 1. Comparison of A.s.o. levels in cord bloods from the two centres

\begin{tabular}{|c|c|c|}
\hline $\begin{array}{l}\text { A.s.o. values } \\
=(u . / m l .)\end{array}$ & Taplow & Hammersmith \\
\hline 25 or less & $59(27 \%)$ & $35(14 \%)$ \\
\hline $\left.\begin{array}{l}\mathbf{5 0} \\
\mathbf{7 5}\end{array}\right\}$ & $\left.\begin{array}{l}38 \\
24\end{array}\right\} 62(28 \%)$ & $\left.\begin{array}{l}29 \\
59\end{array}\right\} 88(34 \%)$ \\
\hline 100$)$ & $50)_{75}(34 \%$ & $68)$ \\
\hline 150$\}$ & $25\}^{75(34 \%)}$ & $33\}^{101(39 \%)}$ \\
\hline 200 and over & $25(11 \%)$ & $35(13 \%)$ \\
\hline Totals & 221 & $259=480$ \\
\hline
\end{tabular}

frequency $(27 \%)$ was nearly twice that of Hammersmith $(14 \%)$. Such a difference might be expected between a relatively rural district (Taplow) and an intensely urban one (Hammersmith). 


\section{(3) A.s.o. levels in the three parity groups}

The distribution of A.s.o. values in the whole investigation is given in Table 2, which shows the frequency of each value in both hospitals and in each parity group. Contrary to expectation, no significant differences in distribution between the three groups were found. The cord bloods from multiparae with school-age children showed rather fewer high values than those of the other groups.

\section{Table 2. The distribution of antistreptolysin-O levels among cord bloods from} primiparae and multiparae delivered at two hospitals in different areas

Cord bloods from primiparae

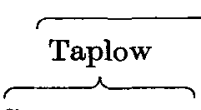

A.s.o.
(u./ml.) $\overbrace{\text { mer }}$ Wum- $\overbrace{\text { mer Winter }}^{\text {Sum }}$

$\begin{array}{llll}25 & 11 & 15\end{array}$

$\begin{array}{rrr}50 & 8 & 14 \\ 75 & 6 & 4\end{array}$

$\begin{array}{lll}100 & 15 & 14\end{array}$

150

200

300

Totals

$\begin{array}{rr}2 & 11 \\ 4 & 7 \\ 15 & 6 \\ 12 & 13 \\ 4 & 9 \\ 1 & 6 \\ 1 & 4 \\ 39 & 56\end{array}$
95

$\begin{array}{rrrr}6 & 10 & 5 & 17 \\ 2 & 5 & 1 & 10 \\ 5 & 1 & 9 & 13 \\ 6 & 5 & 11 & 13 \\ 6 & 2 & 9 & 8 \\ 1 & 4 & 4 & 10 \\ 0 & 2 & 2 & 2 \\ 26 & 29 & 41 & 73\end{array}$

Cord bloods from multiparae

with children under school age

Cord bloods from multiparae with children of school age
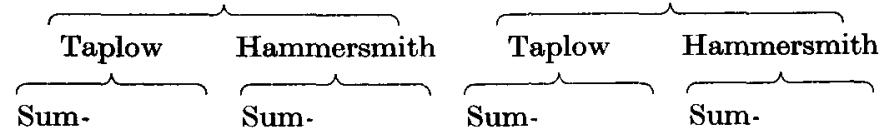

mer Winter

mer Winter
Sum.

mer Winter mer Winter

$\begin{array}{rr}\mathbf{9} & \mathbf{8} \\ \mathbf{5} & \mathbf{4} \\ \mathbf{5} & \mathbf{3} \\ \mathbf{6} & \mathbf{4} \\ \mathbf{2} & \mathbf{4} \\ \mathbf{3} & \mathbf{2} \\ \mathbf{0} & \mathbf{2} \\ \mathbf{3 0} & \mathbf{2 7} \\ & \mathbf{5 7}\end{array}$

$0 \quad 0$

\section{(4) Seasonal differences}

Table 2 includes a comparison of cord-blood A.s.o. levels in 'summer' (MaySeptember 1955) and in 'winter' (October 1955-April 1956). The analysis of these seasonal differences is given in Table 3. While seasonal changes in titre were

Table 3. Distribution of titres of 200 or more in summer and winter in the three parity groups

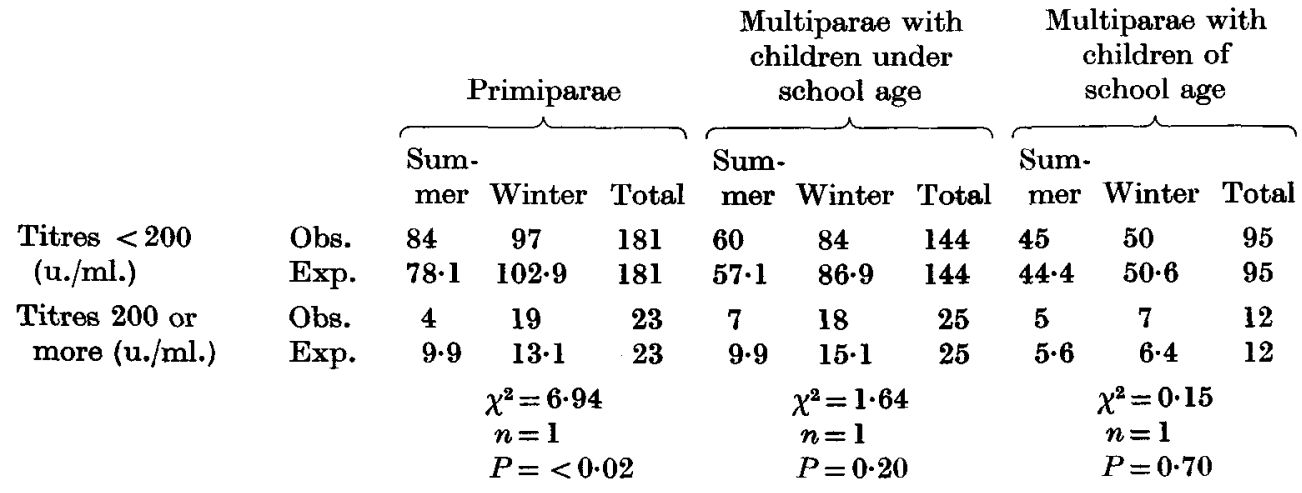


insignificant in the multiparous groups, values of 200 or more were significantly more common in winter in the primiparae. A comparison of the 'summer' figures with the January-April figures only gave similar results.

\section{(5) A.s.o. levels and social class}

The relationship between social class (based upon the Registrar-General's classification of the father's occupation) and A.s.o. levels is shown in Table 4, which indicates a tendency towards higher levels in the lower social classes. A $\chi^{2}$ test confirmed this dependence of antistreptolysin-O level on social class $\left(\chi^{2}=22 \cdot 6\right.$, $n=12, P=$ less than $0 \cdot 05$ ).

Table 4. Distribution of antistreptolysin-O levels between the Registrar-General's social classes 1-5

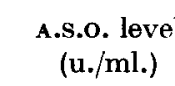

25 or less

$50 / 75$

$100 / 150$

200 or more

Totals

1
$8(42)$
$6(32)$
$4(21)$
$1(5)$
19

$\begin{array}{cc} & \text { Social class } \\ 2 & 3 \\ 10(20) & 58(20) \\ 24(48) & 88(30) \\ 10(20) & 112(37) \\ 6(12) & 39(13) \\ 50 & 297\end{array}$

* Eighteen mothers did not state the fathers' occupation. Percentage of each social class shown in brackets.

\section{DISCUSSION}

Previous workers have shown that the A.s.o. level in cord blood is related to the titre in the mother's blood. In some reports the titre of the two is about the same (Wilson, Wheeler \& Leask, 1934; Vahlquist et al. 1950). Others report that it is sometimes higher in cord blood (Gordon \& Janney, 1941; Rozansky \& Bercovici, 1956) though seldom more than twice the mother's titre (Murray \& Calman, 1953). Our results indicate that a slightly higher titre (about $1 \frac{1}{2}$ times the maternal level at the 36th week of pregnancy) is normally found in cord blood.

On this basis, we were unable to demonstrate any difference in A.s.o. levels between primiparae and multiparae, whether or not the latter had children at school. This unexpected result may be due either to a low incidence of streptococcal infections among the children whose mothers were investigated, or to an increased resistance to streptococci on the part of the multiparous mothers. If children of school age are responsible for an increase in the incidence of familial infection, our failure to show it by the method employed might be due to a greater resistance to streptococcal infection of multiparae. That pregnancy of itself does not increase resistance to streptococcal infections is shown by the comparison of summer and winter A.S.o. levels. In the primiparous group a significant increase in streptococcal infections occurred in winter, as evidenced by the increased winter frequency of higher A.S.o. levels (200 or more) which they showed.

The lack of seasonal variation in the multiparae of both groups may be explicable on similar grounds. Another relevant factor. however, is their decreased 
social mobility. Such mothers, with young children, are largely tied to the home, and may, therefore, undergo minimal exposure to changes in the general streptococcal environment.

This study also shows in general terms the dependence of A.s.o. levels in cord bloods upon the social classes of the families from which the mothers were drawn. In an investigation of school children in Melbourne, Holmes \& Rubbo (1953) found a throat-carrier rate for Streptococcus pyogenes which increased progressively as the economic status of their families decreased. The incidence of rheumatic fever showed a similar increase. However, Hammon, Sather \& Hollinger (1950) in a study of A.S.o. levels in children from poor and rich families respectively, found that there was little difference by the age of 10 years, although a higher level was achieved much earlier in the families at a lower economic level. Our findings suggest that this economic difference occurs also in adults.

\section{SUMMARY}

1. The A.s.o. titre of cord blood is about $1 \frac{1}{2}$ times that in the mother's blood taken 4 weeks before delivery.

2. The distribution of A.S.o. levels in cord bloods from multiparae with children at school is not significantly different from that in multiparae whose children are under school age, or in primiparae.

3. Among these groups, only primiparae show a significantly increased A.s.o. level in winter.

4. The distribution of A.S.o. levels among the five social classes defined by the Registrar-General's occupation code showed a significant trend towards higher levels in the lower social grades.

We wish to thank Mr D. M. W. Maxwell, F.R.C.S., F.R.C.O.G. and Miss D. Slade, S.R.N., S.C.M. at Taplow, and Professor J. C. McC. Browne, F.R.C.S., F.R.C.O.G., Dr W. Hayes, D.Sc., F.R.C.P.I. and Miss M. Tweedle, S.R.N., S.C.M. at Hammersmith Hospital for their kind help.

\section{REFERENCES}

Collins, S. D. (1929). Publ. Hlth Rep., Wash., 44, 763.

Gordon, J. E. \& J ANNey, J. H. (1941). J. Pediat. 18, 587.

Hammon, W. M., Sather, G. E. \& Hollinger, N. (1950). Amer. J. publ. Hlth, 40, 293.

Hewitt, D. \& Stewart, A. (1952). Brit. J. soc. Med. 6, 161.

Holmes, M. C. \& RubBo, S. D. (1953). J. Hyg., Camb., 51, 450.

Johnson, G. D. (1955). J. clin. Path. 8, 296.

Mote, J. R. \& Jones, T. D. (1941). J. Immunol. 41, 35.

Murray, J. \& Calman, R. M. (1953). Brit. med. J. 1, 13.

Rozansky, R.\& Bercovici, B. (1956). Proc. Soc. exp. Biol. Med. 92, 4.

VAhLQUist, B., Lagncrantz, R. \& Nordbring, F. (1950). Lancet, 2, 851.

WANNAMAKer, L. W. (1954). In Streptococcal Infections, p. 161. Ed. McCarty, M., New York. Wilson, M. G., Wheeler, G. W. \& Leask, M. M. (1934). Proc. Soc. exp. Biol., N.Y., $31,1001$.

(MS. received for publication 26. Ix. 56) 